\title{
Recreational Sports and Intra-articular Hip Injuries in Patients Undergoing Hip Arthroscopy for Femoroacetabular Impingement
}

\author{
Jesus Mas Martinez, M.D., Javier Sanz-Reig, Ph.D., Carmen Verdu Roman, M.D., \\ David Bustamante Suarez de Puga, M.D., Enrique Martinez Gimenez, M.D., and \\ Manuel Morales Santias, M.D.
}

\begin{abstract}
Purpose: We aimed to determine the relationship between recreational sports and intra-articular hip injuries in an active population that had undergone hip arthroscopy for femoroacetabular impingement syndrome. Methods: A retrospective review was performed of prospectively collected data from patients undergoing hip arthroscopy between January 2015 and December 2016. Inclusion criteria included patients between 18 and 50 years of age who had participated in recreational sports prior to surgery and had a minimum of a 2-year follow-up. Labral injury was evaluated using the Multicenter Arthroscopic Hip Outcome Research Network classification, and rim chondral injuries were evaluated using the Acetabular Labral Articular Disruptions system. Ligamentum teres tear and psoas impingement were also recorded. Sports were classified as rotational running (soccer, basketball, handball), flexibility (martial arts, dance), asymmetricoverhead (racquet), or endurance (running, swimming, cycling). Primary univariate analysis of sports' independent associations, demographic characteristics, intra-articular hip injuries, and outcomes was performed. Results: Patients included 185 people with a mean age of 36.7 years. Patients participating in rotational running sports and flexibility sports had a significantly greater proportion of rim chondral injuries than those participating in endurance sports or asymmetric overhead sports $(P=0.02)$. Ligamentum teres tears were significantly associated with flexibility sports $(P<0.001)$. A total of $84.7 \%, 67.7 \%, 67.2 \%$, and $71.2 \%$ of patients met minimal clinically important difference levels for the modified Harris Hip Score (mHHS), the Hip Outcome Score (HOS) ${ }^{10}$ questionnaire with activities of daily living (HOS-ADL), the sports subscale (HOS-SSS), and the International Hip Outcome Tool (iHOT-12), respectively; 94.9\%, 66.2\% and 62.7\% met the patient acceptable symptom state for mHHS, HOS-ADL, and HOS-SSS, respectively; 86.7\%, 48.5\%, 47.8\%, and 32.4\% found substantial clinical benefit for mHHS, HOS-ADL, HOS-SSS, and iHOT-12, respectively. Conclusions: Rotational running sports were significantly associated with rim chondral injuries. Flexibility sports were significantly associated with rim chondral injuries and ligamentum teres tears. Athletes participating in these sports are more likely to have intraarticular hip injuries than those in the other sports categories. Level of Evidence: Level IV, prognostic case series.
\end{abstract}

$\mathbf{H}_{8}^{\mathrm{i}}$ ip anatomy may be influenced in different ways, given the sport. ${ }^{1}$ Baseball and tennis have asymmetry side-to-side hip-motion requirements. Cycling

From Hip Unit, Department of Orthopedic Surgery, HLA Clinica Vistahermosa, Alicante, Spain.

The authors report no conflicts of interest in the authorship and publication of this article. Full ICMJE author disclosure forms are available for this article online, as supplementary material.

Received September 1, 2019; accepted April 11, 2020.

Address correspondence to Javier Sanz-Reig, Ph.D., Department of Orthopedic Surgery, HLA Clínica Vistahermosa, Av. de Denia 76, Alicante 03016, Spain.E-mail:jsanz@traumavist.com

(C) 2020 THE AUTHORS. Published by Elsevier Inc. on behalf of the Arthroscopy Association of North America. This is an open access article under the CC BY-NC-ND license (http://creativecommons.org/licenses/by-nc-nd/4.0/). 2666-061X/191060

https://doi.org/10.1016/j.asmr.2020.04.005 and swimming require repetitive hip motion and hip flexion across the anterior aspect of the hip joint. Dance requires supraphysiological ranges of motion. Running sports lead to high loads across the hip joint. Soccer and basketball have traumatic lateral impact mechanisms. Martial arts require high flexion, adduction and internal rotation motions. These high functional demands may cause patients to develop intra-articular hip injuries. ${ }^{2,3}$

Much literature has been published concerning return to sports after hip arthroscopy (HA) for femoroacetabular impingement (FAI), with rates averaging between $87 \%$ and $92 \% .^{4-6}$ Only 1 previous study focused on a sports-specific analysis of the demographic characteristics of high-level and recreational athletes undergoing HA for $\mathrm{FAI}^{1}{ }^{1}$ but little information about specific hip intra-articular injury patterns and sports for 
recreational athletes has been reported. With this information, patients could be informed about the intraarticular hip injuries based on the sports they practiced prior to surgery, the recovery time, the outcomes, and their return to sports. The purpose of this study was to determine the relationship between recreational sports and intra-articular hip injuries in an active population that underwent HA for FAI syndrome. We hypothesized that intra-articular hip injuries would differ in sports with differing biomechanical demands on the hip.

\section{Methods}

This is a retrospective study of a prospective HA database from January 2015 to December 2016 performed in a single hospital in Spain. Inclusion criteria were patients between 18 and 50 years of age undergoing HA and who had participated in recreational sports prior to surgery, with a minimum of a 2-year follow-up. Exclusion criteria were joint space less than $2 \mathrm{~mm}$, Tönnis grade $2-3$ and no sports participation. The Institutional Review Board approved the study, and all participants gave written informed consent to participate.

The indication for HA was hip pain that interfered with sports activities. Activity modification was recommended during the waiting time for HA.

\section{Surgical Procedure}

HA surgery was performed with the patient placed in the supine position on a traction table. Distraction was performed under fluoroscopic guidance. Standard anterolateral, mid-anterior and distal anterolateral portals were performed. Intra-articular hip injuries were documented. The classification of labral injury was evaluated using the Multicenter Arthroscopic Hip Outcome Research Network classification, ${ }^{7}$ and rim chondral injuries were evaluated using the acetabular labral articular disruptions system. ${ }^{8}$ We considered a hypoplastic labrum when the labrum size was smaller than $5 \mathrm{~mm}$, a normal labrum when labrum size was between $5 \mathrm{~mm}$ and $10 \mathrm{~mm}$, and a hyperplastic labrum when labrum size was greater than $10 \mathrm{~mm}$. The location of the measurements of the labrum was the $12 \mathrm{o}^{\prime}$ clock position. Psoas impingements and ligamentum teres tears were also recorded. According to their condition, pincer and labral lesions were treated by acetabuloplasty and refixation of the labrum with suture anchors. Then, traction was released to access the peripheral compartment through an extended T-capsulotomy. Cam deformity was removed by motorized burr and with the assistance of a fluoroscopic image intensifier (Fig 1). Capsular closure was performed in all patients. All HAs were performed by 2 surgeons (J.M.M and J.S.R), who are experienced in treating athletes with FAI. Postoperative rehabilitation protocols included progressive activities for a period of up to 16 weeks. Return to sports was allowed if the patients demonstrate the ability to perform pain-free running, jumping, lateral agility drills, and single-leg squats.

\section{Primary Outcomes}

Patients were asked about their primary sport. We classified the sports as rotational running (soccer, basketball, handball), flexibility (dance, martial arts), contact (rugby), impingement (rowing), asymmetric/ overhead (tennis, paddle), and endurance (running, cycling, swimming). ${ }^{1}$

\section{Secondary Study Variables}

We collected the following variables: age, sex, body mass index, time of symptoms, diagnosis (cam, pincer or mixed FAI), and intra-articular hip injuries.

Preoperative and 2-year follow-up clinical assessments were performed through the modified Harris Hip Score (mHHS), ${ }^{9}$ a self-administered Hip Outcome Score $(\mathrm{HOS})^{10}$ questionnaire, with activities of daily living (ADLs) and sports subscale (SSS) translated into Spanish and validated ${ }^{11}$ and a self- administered short version of the International Hip Outcome Tool (iHOT-12). ${ }^{12}$ At 2-year follow-up, patients were asked to report whether they had returned to participation in their primary sport.

True anteroposterior plain weight-bearing pelvic views and $45^{\circ}$ Dunn views were performed prior to surgery. ${ }^{13}$ Radiographic evidence of pincer-type FAI consisted of the presence of relative acetabular retroversion on the anteroposterior plain pelvic radiograph, as indicated by a crossover sign and a prominent ischial spine sign. ${ }^{14}$ Cam-type morphology was defined as an alpha angle of more than $50^{\circ}$ on the Dunn lateral radiograph. ${ }^{15}$ All radiographs were graded using the Tönnis grading system. ${ }^{16}$ Measurements included the anteroposterior plain pelvic view, the joint space at the middle of the sourcil, ${ }^{17}$ the lateral center-edge angle described by Wiberg, ${ }^{18}$ the Tönnis angle ${ }^{13}$ and, on the Dunn view, the alpha angle. ${ }^{19}$ All radiographs were analyzed by 2 independent experienced surgeons using a picture archiving and communication system (PACS) computer program.

\section{Statistical Analysis}

Statistical analyses were conducted using SPSS software, version 20.0 (IBM, Armonk, NY, USA). We performed univariate analysis of primary sports independent associations, demographic characteristics, intra-articular hip injuries, and outcomes. For categorical variables, we assessed associations using the $\chi^{2}$ test and 2-way tables. For quantitative variables, we used the Student $t$ test and analysis of variance to compare means following assessment of normality through Kolmogorov-Smirnov test. If data distribution did not 
Fig 1. Right hip in a 33-yearold male soccer player; mean time for symptoms, 28 months. Dunn view. (A) Preoperative cam-type morphology, alpha angle $72^{\circ}$. (B) Postoperative correction following femoral osteoplasty, alpha angle $38^{\circ}$.

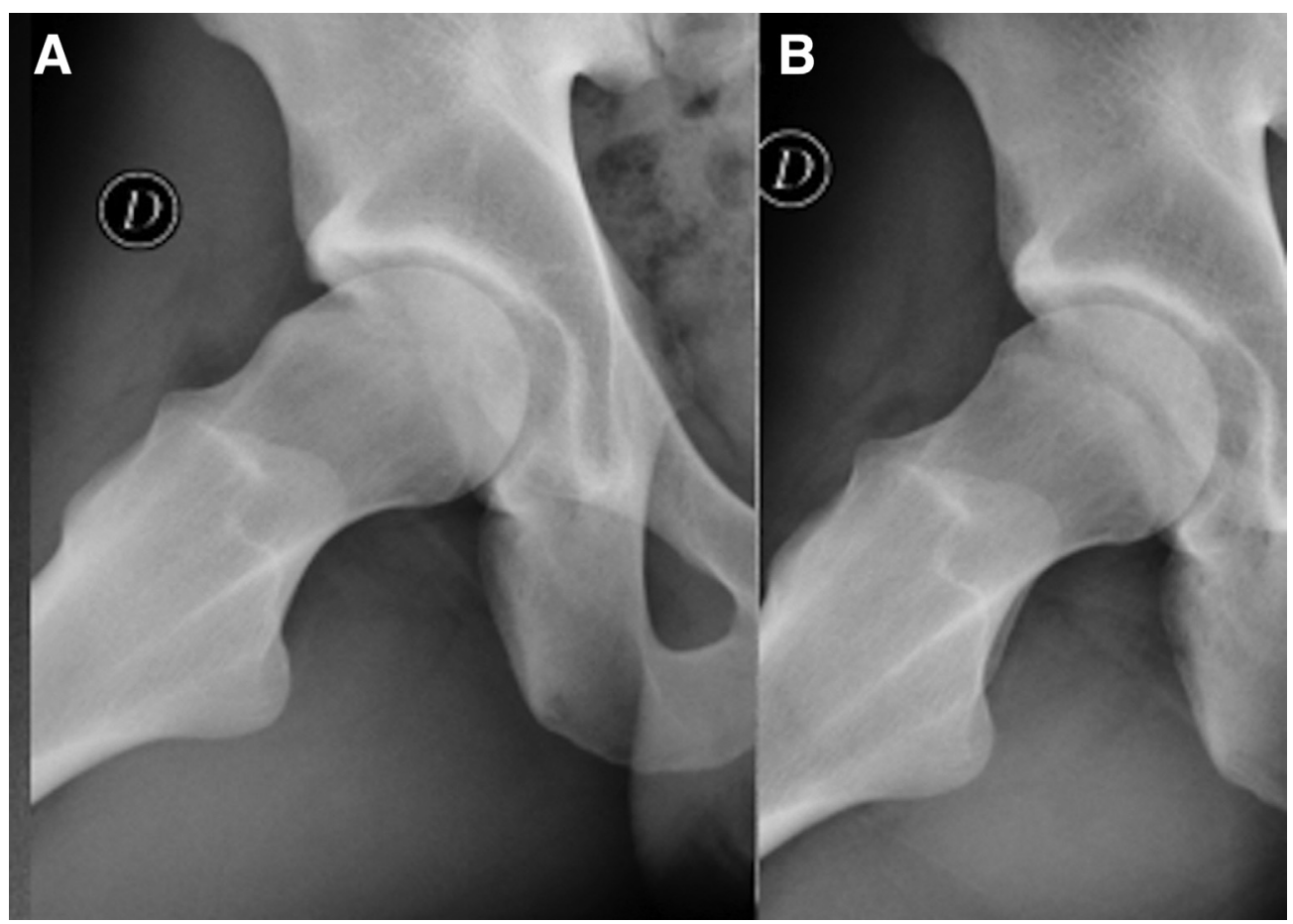

meet normality criteria, the Mann-Whitney $U$ test and Kruskal-Wallis test were used. The post hoc Bonferroni technique was used for all multiple comparisons. Statistical significance was considered to be $P$ values less than 0.05. Clinical relevance was measured by the minimal clinical important difference, patient acceptable symptom state and substantial clinical benefit for mHHS, HOS-ADL and HOS-SSS, and iHOT12. ${ }^{20-22}$

\section{Results}

During the period of the study, 360 patients underwent HA. Among these, 175 patients were excluded: 78 were $<18$ years old or $>50$ years old, 81 were Tönnis grade $2-3$ or had an articular space $<2 \mathrm{~mm}$, and 16 did not participate in sports. The remaining 185 patients were included in the study. The mean age at surgery was 36.7 years (range, 18-50 years). There were 136 male patients $(76.5 \%)$ and 49 female patients $(26.5 \%)$. The mean body mass index was 24.2 (range, 18.4-34.3), and the mean time for symptoms was 20.1 months (range, 4-42 months).

The most common sports were running $(23.2 \%)$, soccer $(17.8 \%)$, cycling $(11.3 \%)$, and martial arts $(11.3 \%)$. Of the patients, $76(41.1 \%)$ practiced endurance sports, $50(27 \%)$ rotational running sports, $36(19.5 \%)$ flexibility sports, $18(9.7 \%)$ asymmetricoverhead sports, $4(2.2 \%)$ contact sports, and $1(0.5 \%)$ impingement sports. Because of the low number of patients practicing contact and impingement sports, these sports were not added to the statistical analysis (Table 1).
There were significant differences in age distribution among sports categories (Table 2). Patients who took part in rotational running sports were significantly younger than patients who played endurance sports $(P=0.003)$ but not with respect to patients who played flexibility sports $(P=0.96)$ or patients who played asymmetric-overhead sports $(P=0.87)$. There were also significant differences in gender distribution among sports categories (Table 2). Male patients took part mostly in rotational running sports, asymmetricoverhead sports and endurance sports, and female patients took part mostly in flexibility sports. The times of symptoms were similar in sports categories (Table 2).

Cam impingement was the most common type of impingement. The mean articular space was $4.8 \pm 0.8$ $\mathrm{mm}$. Patients participating in flexibility sports showed statistically significantly greater articular space than those participating in rotational running sports $(P=0.02)$ but not with respect to endurance sports $(P=1.0)$ or asymmetric overhead sports $(P=0.33)$. The mean alpha angle was $60.9^{\circ} \pm 9.6^{\circ}$, the mean lateral center-edge angle was $33.8^{\circ} \pm 8.0^{\circ}$, and the mean Tönnis angle was $7.2^{\circ} \pm 4.9^{\circ}$. There were no significant differences in these angles among sports categories. (Table 3).

Table 4 shows arthroscopic intraoperative findings. Labrum morphology was normal in 144 hips $(80 \%)$. Hypoplastic labrum was detected predominantly in rotational running sports, and hyperplastic labrum in flexibility sports. Differences in morphology labrum distribution were not significant among sports 
Table 1. Sports Categories for Recreational Athletes

\begin{tabular}{llc}
\hline \multicolumn{1}{c}{ Category } & Type of Sport (N) & Total N (\%) \\
\hline Endurance & $\begin{array}{l}\text { Running (43) } \\
\text { Cycling (21) } \\
\text { Swimming (12) }\end{array}$ & $76(41.1)$ \\
Rotational running & $\begin{array}{l}\text { Soccer (33) } \\
\text { Basketball (11) }\end{array}$ & \\
& Handball (6) \\
Flexibility & Martial arts (21) & $36(19.5)$ \\
Dance (15) & $18(9.7)$ \\
Asymmetric overhead & $\begin{array}{l}\text { Paddle (10) } \\
\text { Tennis (8) }\end{array}$ & $4(2.2)$ \\
Contact & Rugby (4) \\
Impingement & Rowing (1) & $1(0.5)$ \\
\hline
\end{tabular}

categories. Labrum tear was found in 150 hips $(83.3 \%)$, with no significant differences among sports categories. The type of labrum tear was predominantly labralchondral separation, with the greatest proportion in rotational running sports; also, no significant differences were detected among sports categories.

Rim chondral injuries were detected in 147 hips $(81.6 \%)$. Patients participating in rotational running sports and flexibility sports had a greater proportion of rim chondral injuries than those practicing endurance sports or asymmetric overhead sports, and these differences were statistically significant. One was the most common-acetabular labral articular disruption, detected in 61 hips $(33.8 \%)$. There were no significant differences in the distribution of acetabular labral articular disruptions system according to sports categories.

Psoas impingement was found in 16 hips $(8.9 \%)$. A greater proportion was detected in patients taking part in flexibility sports and endurance sports, but these differences were not statistically significant.

Ligamentum teres tears were detected in 16 hips $(8.9 \%)$; the greatest proportion occurred in patients participating in flexibility sports, and these differences were statistically significant $(P=0.001)$.

Patient-reported outcomes improved significantly at the 2-year follow-up. Mean mHHS improved significantly, from 77.2 at baseline to 94.3 at 2 -year follow-up
$(P=0.03)$; HOS-ADLs from 64.1 at baseline to 85.2 at 2 -year follow-up $(P=0.05)$; HOS-SSS from 39.5 at baseline to 72.1 at 2-year follow-up $(P=0.02)$; and iHOT- 12 from 39.1 at baseline to 71.3 at 2-year follow-up $(P=0.01)$. There were no significant differences in preoperative and 2-year patient-reported outcomes among sports categories. Statistically significant improvements were found between preoperative and 2-year mHHS, HOS-ADL, HOS-SSS, and iHOT- 12 in each sports category $(P<0.001)$. The mean change in outcome scores from preoperatively to final follow-up were similar in all sports categories (Table 5). A total of $84.7 \%, 67.7 \%, 67.2 \%$, and $71.2 \%$ of patients met minimal clinically important difference levels for mHHS, HOS-ADL, HOS-SSS, and iHOT-12, respectively; $94.9 \%, 66.2 \%$ and $62.7 \%$ met the patient acceptable symptom state for mHHS, HOS-ADL and HOS-SSS, respectively; $86.7 \%, 48.5 \%, 47.8 \%$, and $32.4 \%$ met substantial clinical benefit for mHHS, HOS-ADL, HOS-SSS, and iHOT-12, respectively.

The rate of return to sports at 2-year follow-up was $82.1 \%$ (152 patients). Return-to-sports rates were 75\% (57 patients) for endurance sports, $80 \%$ (40 patients) for rotational running sports, $86.1 \%$ (31 patients) for flexibility sports, and $100 \%$ (18 patients) for asymmetric-overhead sports. There were no significant differences among sports categories $(P=0.21)$, mean age $(P=0.98)$, sex $(P=0.14)$, mean time for symptoms $(P=0.75)$, alpha angle $(P=0.73)$, labrum tear $(P=0.48)$, acetabular rim articular cartilage lesion $(P=0.8)$, psoas impingement $(P=0.30)$, or ligamentum teres tear $(P=0.40)$ among patients who did return to sports and patients who did not. Outcome mean values showed significant differences among patients who did return to sports versus those who did not (mHHS 96.9 vs 83.8, $P=0.004$; HOS-ADL 92.0 vs 54.8, $P<0.001$; HOS-SSS 84.4 vs 30.0, $P<0.001$; iHOT-12 79.7 vs $31.9, P<0.001)$.

Ten patients $(5.4 \%)$ underwent repeated HA for reshaping cam deformity because of an inadequate resection at the first operation. No patient underwent conversion to arthroplasty.

Table 2. Analysis of Age, Gender and Time of Symptoms

\begin{tabular}{|c|c|c|c|c|c|c|}
\hline & $\begin{array}{c}\text { Endurance } \\
(\mathrm{N}=76)\end{array}$ & $\begin{array}{c}\text { Rotational } \\
\text { Running }(\mathrm{N}=50)\end{array}$ & $\begin{array}{l}\text { Flexibility } \\
(\mathrm{N}=36)\end{array}$ & $\begin{array}{c}\text { Asymmetric } \\
\text { Overhead }(\mathrm{N}=18)\end{array}$ & $\begin{array}{c}\text { Total } \\
(\mathrm{N}=180)\end{array}$ & $P$ \\
\hline$\overline{\text { Age (years) }}$ & $38.8 \pm 7.2$ & $33.7 \pm 7.7$ & $36.1 \pm 7.3$ & $36.8 \pm 7.2$ & & 0.005 \\
\hline \multicolumn{7}{|l|}{ Gender $^{\dagger}$} \\
\hline Female & $22(29)$ & $2(4)$ & $22(61.2)$ & $3(16.7)$ & $49(27.3)$ & \\
\hline Time of symptoms (months) & $18.8 \pm 5.8$ & $21.2 \pm 6.9$ & $24.1 \pm 5.5$ & $18.5 \pm 9.6$ & & 0.51 \\
\hline
\end{tabular}


Table 3. Radiographic Variables

\begin{tabular}{|c|c|c|c|c|c|c|}
\hline & $\begin{array}{l}\text { Endurance } \\
(\mathrm{N}=76)\end{array}$ & $\begin{array}{c}\text { Rotational } \\
\text { Running }(\mathrm{N}=50)\end{array}$ & $\begin{array}{l}\text { Flexibility } \\
(\mathrm{N}=36)\end{array}$ & $\begin{array}{c}\text { Asymmetric } \\
\text { Overhead }(\mathrm{N}=18)\end{array}$ & $\begin{array}{c}\text { Total } \\
(\mathrm{N}=180)\end{array}$ & $P$ \\
\hline \multicolumn{7}{|l|}{$\overline{\mathrm{Cam}}$} \\
\hline Yes & $63(82.8)$ & $39(78)$ & $27(75)$ & $16(88.8)$ & $145(80.5)$ & 0.57 \\
\hline \multicolumn{7}{|l|}{ Pincer } \\
\hline Yes & $31(40.7)$ & $22(44)$ & $18(50)$ & $10(55.5)$ & $81(45)$ & \multirow[t]{2}{*}{0.83} \\
\hline No & $45(59.3)$ & $28(56)$ & $18(50)$ & $8(44.5)$ & $99(55)$ & \\
\hline Cam & $42(55.2)$ & $25(50)$ & $17(47.2)$ & $11(61.2)$ & $95(52.7)$ & \multirow{2}{*}{0.26} \\
\hline Pincer & $7(9.3)$ & $1(2)$ & $5(14)$ & - & $13(7.3)$ & \\
\hline Articular space* & $4.8 \pm 0.7$ & $4.5 \pm 0.5$ & $5.0 \pm 1.0$ & $4.8 \pm 0.9$ & & 0.03 \\
\hline LCEA & $33.0 \pm 8.5$ & $36.6 \pm 6.0$ & $32.6 \pm 8.3$ & $33.5 \pm 8.2$ & & 0.17 \\
\hline Tönnis angle & $7.3 \pm 2.8$ & $6.4 \pm 3.8$ & $7.2 \pm 3.7$ & $8.9 \pm 3.1$ & & 0.61 \\
\hline Alpha angle & $60.4 \pm 10.6$ & $62.7 \pm 8.7$ & $58.6 \pm 8.6$ & $62.8 \pm 8.1$ & & 0.20 \\
\hline
\end{tabular}

\section{Discussion}

We found differences in the intra-articular hip injury patterns of recreational athletes. Players of endurance sports had the greatest proportion of labral tears. Rotational running sports players had a higher proportion of hypoplastic labrum, labral-chondral separation and rim chondral injuries. Flexibility sports players had a higher proportion of hyperplastic labrum, acetabular rim articular cartilage lesions and ligamentum teres tears. Asymmetric-overhead players had the lowest proportion of labrum tears and rim chondral injuries but no psoas impingement or ligamentum teres tears.

Biomechanical hip stress differs according to the type of sport. ${ }^{5}$ Endurance sports require extended periods of repetitive hip motion. Rotational running sports demand changes of direction and cutting, with high rotational loads across the hip. Flexibility sports players subject their hips to supraphysiological motions. Asymmetric overhead sports have side-to-side functional hip motion differences. These differences in mechanical demands by sport may be the cause of the variance in intra-articular HA findings.

Research in athletes undergoing HA has focused on return to sports, and researchers publish general demographic data, intraoperative findings and surgical procedures. ${ }^{2,3,5,6,23}$ To our knowledge, few publications have studied differences among the athletes involved in various sports.

Nawabi et al. ${ }^{1}$ reported the surgical procedures in 228 high-level and 334 recreational athletes undergoing HA for FAI in a retrospective study. In high-level athletes they found a greater proportion of combined cam and rim decompression and labral refixation in endurance sports and rotational running sports, and they found a greater proportion of ligamentum teres debridement and psoas release in flexibility sports. Our results also show differences for recreational athletes, but few of them were statistically significant. Patients participating in endurance sports had the greatest proportion of labral tears; in rotational sports, patients had the presence of hypoplastic labrum, labral-chondral separations, labrum tears, and rim chondral injuries; and in flexibility sports, patients had the presence of hyperplastic labrum, psoas impingement and ligamentum teres tears. These findings support the idea that sports categories may predict particular patterns of intraarticular hip injury.

Patients taking part in rotational sports were significantly younger than those in other sports categories. Nawabi et al. ${ }^{1}$ Malviya et al. ${ }^{24}$, and Nogier et al. ${ }^{25}$ reported similar age for recreational athletes. However, Carton et al. ${ }^{26}$ reported younger ages in their study of 1,021 competitive athletes. Studies that included high-level athletes and recreational athletes reported younger ages for high-level athletes ${ }^{1}$ or similar ages. ${ }^{24}$ Male gender was more prevalent in our study, with $72 \%$ or more than that found in other studies: $57 \%^{1}$ and $62 \%{ }^{24,25}$ Carton et al. $^{26}$ reported higher prevalence of male gender, $93 \%$, in their study. These demographic differences among studies may be related to the sports and exercise culture in each country.

This study did not demonstrate significant differences among sports categories in cam or pincer morphology on radiological views . Cam impingement was the most common type of FAI. Patients participating in flexibility sports had the greatest articular spaces and the lowest lateral center-edge angles. The mean alpha angle was $60.9^{\circ}$ in our study, and it was similar to that found in other studies: $62.8^{\circ}$ for high-level athletes ${ }^{1} ; 60^{\circ}$ for 
Table 4. Arthroscopic Intraoperative Findings

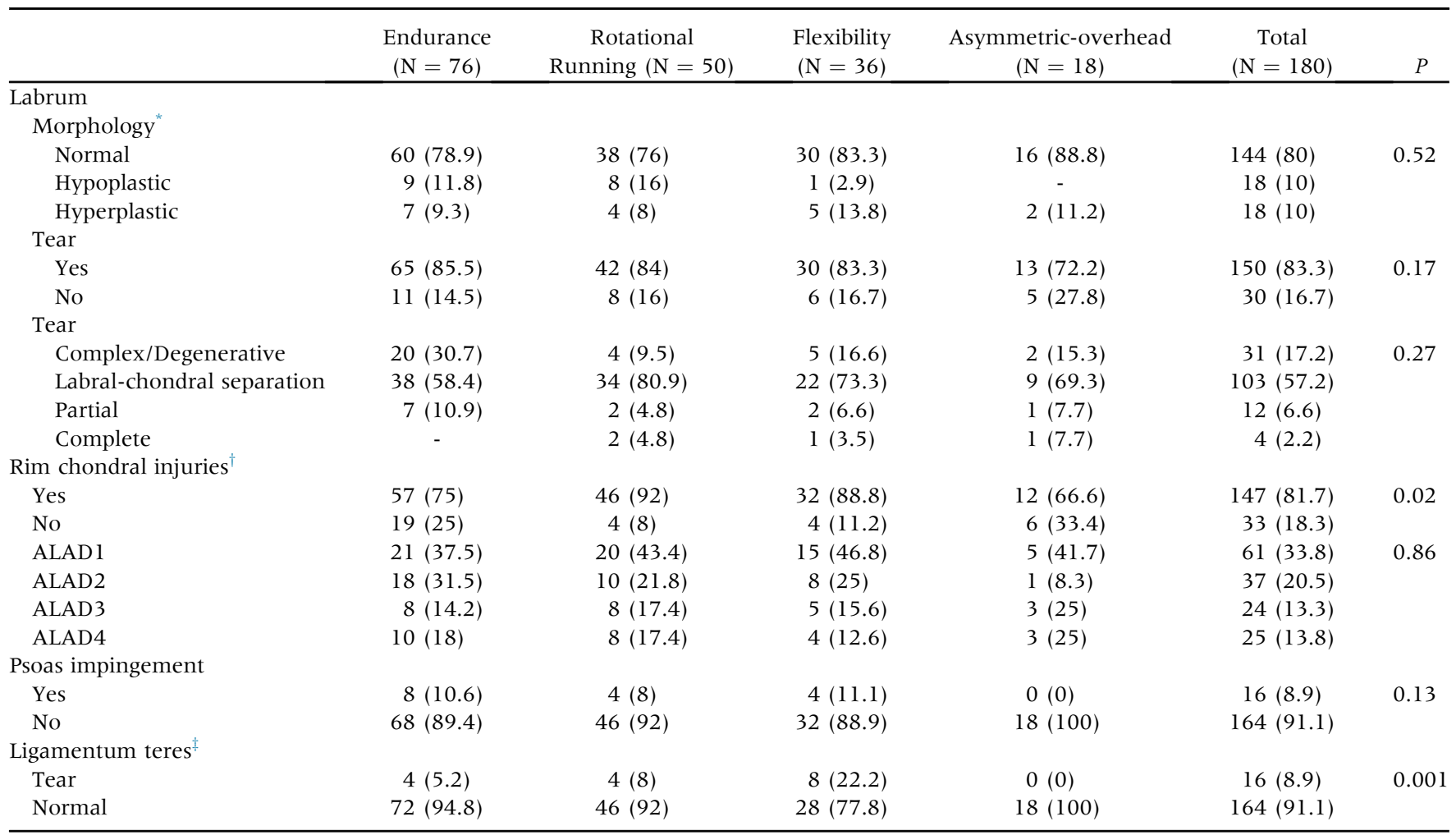

NOTE. Values are presented as $\mathrm{N}(\%)$.

ALAD, acetabular labral articular disruptions system.

*Normal labrum: 5-10 mm size; hypoplastic labrum: less than $5 \mathrm{~mm}$ size; hyperplastic labrum: greater than $10 \mathrm{~mm}$ size.

${ }^{\dagger}$ Rotational running sports and flexibility sports showed a significantly greater proportion than endurance and asymmetric-overhead sports in rim chondral injuries.

${ }^{\ddagger}$ Flexibility sports showed a significantly greater proportion of ligamentum teres tears than rotational running, endurance or asymmetricoverhead sports.

high-level athletes and $59^{\circ}$ for recreational athletes ${ }^{24}$; and $61^{\circ}$ for professional athletes. ${ }^{26}$ The mean alpha angles among sports categories were also similar to the data reported by Nawabi et al. ${ }^{1}$ for high-level athletes: for endurance sports, $60^{\circ}$ in our study compared to $55.8^{\circ}$; for rotational running sports, $62^{\circ}$ in our study

Table 5. Patient-Reported Outcomes

\begin{tabular}{|c|c|c|c|c|c|}
\hline & Endurance $(\mathrm{N}=76)$ & Rotational Running $(\mathrm{N}=50)$ & Flexibility $(\mathrm{N}=36)$ & Asymmetric-Overhead $(\mathrm{N}=18)$ & $P$ \\
\hline \multicolumn{6}{|l|}{$\overline{\mathrm{mHHS}^{*}}$} \\
\hline Preop & $77.8 \pm 8.2$ & $77.7 \pm 6.9$ & $77.1 \pm 11.1$ & $75.1 \pm 9.3$ & 0.68 \\
\hline 2-year follow-up & $94.1 \pm 8.9$ & $96.7 \pm 6.0$ & $93.4 \pm 9.9$ & $92.2 \pm 10.1$ & 0.63 \\
\hline \multicolumn{6}{|l|}{ HOS-ADL* } \\
\hline Preop & $62.5 \pm 18.1$ & $64.7 \pm 19.0$ & $67.5 \pm 17.7$ & $66.1 \pm 21.2$ & 0.67 \\
\hline 2-year follow-up & $82.9 \pm 21.2$ & $81.5 \pm 23.7$ & $89.6 \pm 14.7$ & $93.7 \pm 7.8$ & 0.54 \\
\hline Preop & $36.0 \pm 21.7$ & $44.2 \pm 24.2$ & $42.3 \pm 21.2$ & $32.9 \pm 23.1$ & 0.19 \\
\hline 2-year follow-up & $68.1 \pm 20.2$ & $70.1 \pm 21.2$ & $75.0 \pm 22.6$ & $71.0 \pm 19.6$ & 0.53 \\
\hline$\Delta$ & $34.9 \pm 13.1$ & $36.4 \pm 10.1$ & $27.6 \pm 14.5$ & $40.5 \pm 15.2$ & 0.83 \\
\hline \multicolumn{6}{|l|}{ iHOT- $12 *$} \\
\hline Preop & $37.2 \pm 18.8$ & $38.0 \pm 18.9$ & $37.2 \pm 20.8$ & $49.4 \pm 20.7$ & 0.22 \\
\hline 2-year follow-up & $67.6 \pm 20.2$ & $67.5 \pm 21.6$ & $74.9 \pm 1.7$ & $70.4 \pm 18.5$ & 0.32 \\
\hline
\end{tabular}

ADL, activities of daily living; $\Delta$, mean change in patient-reported outcomes scores from preoperatively to 2 years postoperatively.

${ }^{*}$ Mean \pm SD. 
compared to $61.4^{\circ}$; for flexibility sports, $58^{\circ}$ in our study compared to $57.9^{\circ}$; and for asymmetric overhead sports, $62^{\circ}$ in our study compared to $63.5^{\circ}$.

Some theories exist regarding the increased prevalence of cam morphology in relation to sports practice. Participation in vigorous sporting activities appears to be the most important factor for the development of idiopathic cam morphology. ${ }^{27}$ Nawabi et al. ${ }^{1}$ found greater mean alpha angles in contact and impingement sports. We did not find statistically significant differences in mean alpha angle among sports categories.

Our outcome measures were similar to outcomes after HA for FAI. ${ }^{4,28-30}$ There were no differences among sports categories preoperatively or at final follow-up. The mean change in outcome scores was also similar among sports categories, and they were higher than the minimal clinically important difference for mHHS, ${ }^{21}$ HOS-ADL, ${ }^{21}$ HOS-SSS, ${ }^{21}$ and iHOT- $12 .{ }^{22}$

Several studies examined return to sports after HA among athletes of all levels in the short term. Malviya et al. ${ }^{24}$ reported rates of $88 \%$ and $73 \%$ in 40 professional and 40 recreational athletes at 1.4-year follow-up. Brunner et al. ${ }^{31}$ referred to rates of $68.9 \%$ in 45 recreational athletes at the 2.4-year follow-up. And Weber et al. ${ }^{32}$ found, in 66 patients, 49 recreational and 17 high-level amateur athletes, a rate of return to sports of $88 \%$ in high-level amateurs and $94 \%$ in recreational athletes at a 2 -year follow-up. Our study showed a rate of return to sports of $82.1 \%$ in our population of recreational athletes at 2-year follow-up. There were no significant differences among sports categories, and outcome mean values were significantly higher for patients who did return to sports. Other studies also demonstrate higher outcome values in patients who returned to sports. ${ }^{23,33}$

Our study has several strengths. First, data were collected prospectively, and the study has well-established criteria and aims. Second, this was a study of recreational athletes in 4 sports categories that included the vast majority of recreational sports. Third, sports categories based on biomechanical hip stress is a novel concept.

\section{Limitations}

There are limitations to this study. First, the classification of sports categories is subjective. It is based on observations made by 2 authors who are experienced in assessing and treating athletes with FAI. Second, there is an influence of the age at which patients present with symptoms. We have found significant differences between rotational sports and the other sports categories. Third, our patients were asked about their primary sport, not about the level of activity, the time during which the patient had been practicing the sport or the specific sports discipline, which is a possible selection bias. Last, we did not use computed tomography scans to define pincer morphology.

\section{Conclusions}

Rotational running sports were significantly associated with rim chondral injuries. Flexibility sports were significantly associated with rim chondral injuries and ligamentum teres tears. Athletes participating in these sports are more likely to have these intra-articular hip injuries than those in the other sports categories.

\section{References}

1. Nawabi DH, Bedi A, Tibor LM, Kelly BT. The demographic characteristics of high-level and recreational athletes undergoing hip arthroscopy for femoroacetabular impingement: A sports-specific analysis. Arthroscopy 2014;30: 398-405.

2. Jackson TJ, Starkey C, McElhiney D, Domb BG. Epidemiology of hip injuries in the National Basketball Association: A 24-Year overview. Orthop J Sports Med 2013;12(1):2325967113499130.

3. Gerhardt MB, Romero AA, Silvers HJ, Harris DJ, Watanabe D, Mandelbaum B. The prevalence of radiographic hip abnormalities in elite soccer players. Am J Sports Med 2012;40:584-588.

4. Tjong VK, Cogan CJ, Riederman BD, Terry MA. A qualitative assessment of return to sport after hip arthroscopy for femoroacetabular impingement. Orthop J Sports Med 2016:4:2325967116671940.

5. Lee S, Kuhn A, Draovitch Bedi A. Return to play following hip arthroscopy. Clin Sports Med 2016;35. doi:10. 1016/j.csm.2016.05.008.

6. Reiman MP, Peters S, Sylvain J, Hagymasi S, Mather RC, Goode AP. Femoroacetabular impingement surgery allows $74 \%$ of athletes to return to the same competitive level of sports participation, but their level of performance remains unreported: A systematic review with metaanalysis. Br J Sports Med 2018;52:972-981.

7. Freehill MT, Safran MR. The labrum of the hip: Diagnosis and rationale for surgical correction. Clin Sports Med 2011;30:293-315.

8. Safran MR. Hip arthroscopy assessments: Tools and outcomes. Oper Tech Orthop 2010;20:264-277.

9. Ranawat AS, Kelly BT. Function of the labrum and management of labral pathology. Operat Techn Orthoped 2005; 15:239-246.

10. Martin RL, Philippon MJ. Evidence of validity for the hip outcome score in hip arthroscopy. Arthroscopy 2007;23: 822-826.

11. Seijas R, Sallent A, Ruiz-Iban MA, Ares O, Marin-Peña O, Cuellar R, et al. Validation of the Spanish version of the Hip Outcome Score: A multicenter study. Health Qual Life Outcom 2014;12:70.

12. Griffin DR, Parsons N, Mohtadi NG, Safran MR. Multicenter Arthroscopy of the Hip Outcomes Research N: A short version of the International Hip Outcome Tool (iHOT-12) for use in routine clinical practice. Arthroscopy 2012;28:611-616.

13. Clohisy JC, Carlisle JC, Beaulé PE, Kim Y, Trousdale RT, Sierra RJ, et al. A systematic approach to the plain radiographic evaluation of the young adult hip. J Bone Joint Surg Am 2008;90:47-66. 
14. Werner CM, Copeland CE, Ruckstuhl T, Stromberg J, Turen CH, Kalberer F. Radiographic markers of acetabular retroversion: Correlation of the cross-over sign, ischial spine sign and posterior wall sign. Acta Orthop Belg 2010;76: 166-173.

15. Barton C, Salineros MJ, Rakhra KS, Beaule PE. Validity of the alpha angle measurement on plain radiographs in the evaluation of cam type femoroacetabular impingement. Clin Orthop Relat Res 2011;469:464-469.

16. Tönnis D. Congenital dysplasia and dislocation of the hip in children and adults. Berlin, Germany: Springer, 1987.

17. Philippon MJ, Briggs KK, Yen YM, Kuppersmith DA. Outcomes following hip arthroscopy for femoroacetabular impingement with associated chondrolabral dysfunction: Minimum two-year follow-up. J Bone Joint Surg 2009;91: 16-23.

18. Wiberg G. Shelf operation in congenital dysplasia of the acetabulum and in subluxation and dislocation of the hip. J Bone Joint Surg Am 1953;35:65-80.

19. Bedi A, Kelly BT. Femoroacetabular impingement. J Bone Joint Surg Am 2013;95:82-92.

20. Harris JD, Brand JC, Cote MP, Faucett SC, Dhawan A. Research pearls: The significance of statistics and perils of pooling. Part 1: Clinical versus statistical significance. Arthroscopy 2017;33:1102-1112.

21. Nwachukwu BU, Chang B, Fields K, Rebolledo BJ, Nawabi DH, Kelly BT, et al. Defining the "substantial clinical benefit" after arthroscopic treatment of femoroacetabular impingement. Am J Sports Med 2017;45:1297-1303.

22. Martin RL, Kivlan BR, Christoforetti JJ, Wolf AB, Nho SJ, Salvo JP, et al. Minimal clinically important difference and substantial clinical benefit values for the 12-item International Hip Outcome Tool. Arthroscopy 2019;35:41 1-416.

23. Perets I, Craig MJ, Mu BH, Maldonado DR, Litrenta JM, Domb BG. Midterm outcomes and return to sports among athletes undergoing hip arthroscopy. Am J Sports Med 2018;46:1661-1667.

24. Malviya A, Paliobeis CP, Villar RN. Do professional athletes perform better than recreational athletes after arthroscopy for femoroacetabular impingement? Clin Orthop Relat Res 2013;471:2477-2483.

25. Nogier A, Bonin N, May O, Gedouin JE, Bellaiche L, Boyer T, et al. Descriptive epidemiology of mechanical hip pathology in adults under 50 years of age: Prospective series of 292 cases: Clinical and radiological aspects and physiopathological review. Orthop Trauma Surg Res 2010;96:S53-S58.

26. Carton PF, Filan DJ. The clinical presentation, diagnosis and pathogenesis of symptomatic sports-related femoroacetabular impingement (SRFAI) in a consecutive series of 1021 athletic hips. Hip Int 2019:1120700018825430.

27. Morris WZ, Li RT, Liu RW, Salata MJ, Voos JE. Origin of cam morphology in femoroacetabular impingement. Am J Sports Med 2018;46:478-486.

28. Byrd JW. Femoroacetabular impingement in athletes: Current concepts. Am J Sports Med 2014;42:737-751.

29. Nho SJ, Magennis EM, Singh CK, Kelly BT. Outcomes after the arthroscopic treatment of femoroacetabular impingement in a mixed group of high-level athletes. Am J Sports Med 2011;39:14S-19S.

30. Sansone M, Ahldén M, Jónasson P, Thomeé C, Sward L, Öhlin A, et al. Outcome after hip arthroscopy for femoroacetabular impingement in 289 patients with minimum 2-year follow-up. Scand J Med Sci Sports 2017;27:230-235.

31. Brunner A, Horisberger M, Herzog RF. Sports and recreation activity of patients with femoroacetabular impingement before and after arthroscopic osteoplasty. Am J Sports Med 2009;37:917-922.

32. Weber AE, Kuhns BD, Cvetanovich GL, Grzybowski JS, Salata MJ, Nho SJ. Amateur and recreational athletes return to sport at a high rate following hip arthroscopy for femoroacetabular impingement. Arthroscopy 2017;33: 748-755.

33. Domb BG, Dunne KF, Martin TJ, Gui C, Finch NA, Vemula SP, et al. Patient-reported outcomes for patients who returned to sport compared with those who did not after hip arthroscopy: Minimum 2-year follow-up. J Hip Preserv Surg 2016;3:124-131. 